\title{
Nataliya Tchermalykh
}

\section{Caitlyn Collins. Making Motherhood Work: How Women Manage Careers and Care- giving. Princeton, NJ: Princeton University Press, 2019. 360 pp. ISBN 978-0- 6911-7885-1.}

Nataliya Tchermalykh, Centre for Children's Rights Studies, University of Geneva. Address for correspondence: Valais Campus, PO Box 4176, CH 1950 Sion 4, Switzerland. nataliya.tchermalykh@graduateinstitute.ch.

Making Motherhood Work: How Women Manage Careers and Caregiving by Caitlyn Collins is one of those deeply researched and particularly well-written volumes in the social sciences that will be of equal interest to gender scholars and feminist activists, but also easily accessible to novices. At least this was my experience of the book: I read it in its entirety (all 300 pages with appendices!), from cover to cover, over the course of one long day.

Although its main focus is European and American work-family policies-studied comparatively - which is a bit outside of my primary area of interest, I was captivated by Collins's narrative thread, sophisticated argumentation, and political appeals. Perhaps my own experience of this book was plural: at times I read it as a feminist who cannot but help imagining a better world for women with children; at other times as an anthropologist, stimulated by the rich ethnographic material of the book; and also as a (working) mother, often drawn to compare diverse experiences of motherhood to my own.

Collins describes her research as a systematic, cross-national comparative study of how women in three European countries (Sweden, Germany, Italy) and the United States perceive and experience motherhood and employment in light of the welfare policies available to them. The main criteria for the selection of cases in the book was therefore to shed light on four distinct welfare state regimes: social democratic for Sweden, conservative for Germany, familialist for Italy, and liberal for the US. The book is divided accordingly into seven chapters covering five cases. Eastern Germany (former GDR) and Western Germany (former FRG) are considered as two distinct areas, which is a significant detail that adds a cross-temporal dimension to the study. These chapters will undoubtedly be useful for those who study the evolution of gender-related welfare policies in postsocialist countries, including the former USSR.

In her analysis Collins presents the macrosocietal factors (sociopolitical regimes and policies) as central explanatory variables that critically impact the object of her research. To describe these impacts comprehensively, she introduces a compelling concept, "lifeworlds of motherhood," which she defines as "a distinctive social universe of individual experiences, interactions, organizations, and institutions shaping the employment and childrearing possibilities that women can envision for themselves" (p. 6). 
Such conceptualization situates Collins's study closer to the spectrum of feminist anthropology (it is a pity, though, that the notion of "lifeworlds of motherhood" is not developed deeper throughout the book), as does Collins's methodology: it is a vast qualitative investigation engaging 150 in-depth interviews collected face-toface across different field sites. Just as Pamela Stone (2008) did ten years ago in Opting Out? Why Women Really Quit Careers and Head Home, Collins chooses to interview predominantly middle-class mothers who are fully or partially employed in wealthy parts of the world, defined interchangeably as "the developed world" or "the industrialized West."

While the author herself several times fully admits the limitations of disregarding such factors as class, race, social origin, education, and residency or citizenship status in the experiences of motherhood, it seems quite questionable to reduce the experience of those whose life trajectory is shaped by "the lifelong set of cumulative disadvantages" to a single statement that "things are much harder for them" ( $p$. 199). The body of feminist scholarship developed over the last decades around Kimberlé Williams Crenshaw's concept of intersectionality (Cho, Crenshaw, and McCall 2013) is, by the way, unacknowledged in the book's literature review. Collins's conscious and persistent focus on a single macrolevel factor does not diminish the value of this outstanding research (much to the contrary); yet, one question remains: why is the privileged form of motherhood, rather than the unprivileged, considered the most sensitive beneficiary - and the most neutral case-against which to measure the failures or successes of evolving state policies?

As mentioned earlier, I read Collins's entire volume in one day. In fact, I read it during a 10-hour trip from Switzerland to Ukraine, travelling by train from Geneva to Milan and then by low-cost flight from Milan to Kiev. On that plane, while deeply absorbed in reading and note-taking for Making Motherhood Work, I found myself in the middle seat, between two women. To my right sat a 50-something Ukrainian woman. As I found out later, when she proudly showed me videos of her grandson running in the yard in a scene typical of the Ukrainian countryside, she was a lifelong migrant employed in caregiving in Italy in order to support a growing family that she had left in her country of origin. To my left sat an Italian woman in her late twenties. We didn't talk. She was traveling alone and was reading simultaneously two books about cultural history and arts. A glimpse at her phone screen (I don't know to what extent my "ethnographic glimpses" were even ethical!) informed me that she was also a mother, as her screen featured a picture of herself lovingly hugging her young daughter.

This setting appeared almost as a living illustration for Making Motherhood Work. A working mother and a noncitizen migrant worker myself, I was literally sitting in the middle, both physically and socially. Intellectually and professionally I was closer to my neighbor on the left, yet in terms of social vulnerability my experiences are likely closer to my neighbor on the right. And yet, from among our range of social experiences across the airplane row, only the young Italian woman would have been eligible under Collins's sampling. 
Here is one of the examples where a different experience of motherhood appears in the background of the type described by Collins: "Elena is a marketing manager for an international finance company. She typically works ten-hour days, arriving home around 8:30 every evening. She employs a full-time housekeeper and nanny named Oksana, who is a single mother from the Ukraine" (p. 151). If the reader knew who is looking after Oksana's child while she works for Elena-and, more importantly, what Oksana thinks about her employer-the social configuration of the Italian (and perhaps also the Ukrainian) welfare system would appear more complex. Such examples, equally representative of the consequences of insufficient state policies and of shifting cross-European patterns of female work migration, spur us to think beyond national divides to understand how women manage careers and caregiving-not only in different countries but also in different social arenas.

In her writing, Collins sharpens the tension between the two necessary, yet often irreconcilable, poles of the life of an employed mother- "family" and "work"rejecting the idea of "work-family balance" for a more radical one-"work-family conflict." "Mothers don't need balance. They need justice," concludes Collins (p. 7). Work-family justice is here presented simultaneously as an analytical concept related to individual experiences in contexts shaped by institutional politic and also as a specific goal for feminist policymaking. One can only applaud these prospects and anticipate more comparative research in other geographic areas and field sites to come-especially studies conducted across the divides of class and origin.

\section{REFERENCES}

Cho, Sumi, Kimberlé Williams Crenshaw, and Leslie McCall. 2013. “Toward a Field of Intersectionality Studies: Theory, Applications, and Praxis." Signs: Journal of Women in Culture and Society 38(4):785-810.

Stone, Pamela. 2008. Opting Out? Why Women Really Quit Careers and Head Home. Berkeley: University of California Press. 